\title{
Incidental detection of atypical endometriosis during caesarean section suspicious of malignancy-a case
} report

\begin{abstract}
Endometriosis is defined as presence of endometrium including glands and stroma at locations other than the uterine cavity. Atypical endometriosis is rarely seen, accounting for $4.38 \%$ amongst endometriosis cases and is reported to possess a precancerous potential. We are reporting a case of primigravida with term gestation, taken up for emergency caesarean section in view of severe preeclampsia with imminent signs of eclampsia. Intraoperatively left ovary was adherent to posterior uterine wall and a cauliflower like growth was seen extending from posterior part of left mesosalphinx, left ovary, posterior uterine wall upto pouch of douglas. Biopsy was taken from the growth and its histopathological examination was reported as atypical endometriosis. Postoperatively patient was stable and was discharged on postoperative day 8 .
\end{abstract}

Volume 6 Issue 5 - 2018

Tejaswini B, Chandushree, Ashok Kumar, Bharathi, Sumayya, Shruthi K, Sreelatha S Department of Obstetrics \& Gynaecology, ESIC-MC \& PGIMSR, India

Correspondence: Sreelatha S, Professor, Department of Obstetrics \& Gynaecology, ESIC-MC \& PGIMSR, Bangalore, India,Tel 94489I5477, Email drsreeletha201 I@gmail.com

Received: August 23, 2018 | Published: October 30, 2018

Keywords: atypical endometriosis, pregnancy, ceasaeean section, imminent eclampsia, malignant potential

\section{Introduction}

Endometriosis is a benign disease defined by the presence of endometrial glands and stroma outside the uterus. Examination of the ovaries at caesarean section is a normal practice as ovarian pathology may be found. The incidence of an adnexal mass found at caesarean section ranges from 1 in 1231 to 3292. About 20-25\% of women have asymptomatic endometriosis. ${ }^{1}$ Endometriosis affects $6 \%$ to $10 \%$ of reproductive age women 6 . Approximately $1 \%$ to $4 \%$ of pregnant women are diagnosed with an ovarian mass. Of all the adnexal masses reported during pregnancy the incidence of ovarian endometriosis varies widely from $5 \%$ to $30 \%$.,3 We are reporting a case of incidentally found atypical endometriosis at emergency caesarean section.

\section{Case report}

A 32-year-old primigravida, married for one year, conceived spontaneously without any history of infertility was registered with us for antenatal care. At 39+2 weeks of gestation she came with h/o pain abdomen and headache and was admitted in labor room. BP at admission was 140/90 and headache was persistent even after analgesics and antihypertensives. She was taken up for emergency lower segment cesarean section (LSCS) in view of imminent eclampsia and bad bishop score after giving a loading dose of $\mathrm{MgSO}_{4}$. After the delivery of fetus, intraoperatively left ovary was adherent to posterior uterine wall and a highly vascular cauliflower like growth was seen extending from posterior part of left mesosalphinx, left ovary, posterior uterine wall upto pouch of douglas (Figure 1). Left fallopian tube was free and right side ovary and tube were normal. Biopsy was taken from the growth and its histopathological examination was reported as atypical endometriosis (Figure 2). Markers for ovarian carcinoma (Beta HCG, LDH,CA-125, CEA, AFP) were within normal limits. Ultrasonogram done on post operative day 7 , reported it as an echogenic lesion, could be endometriosis. Her course in the ward postoperatively was uneventful. Patient was discharged on postoperative day 8 .

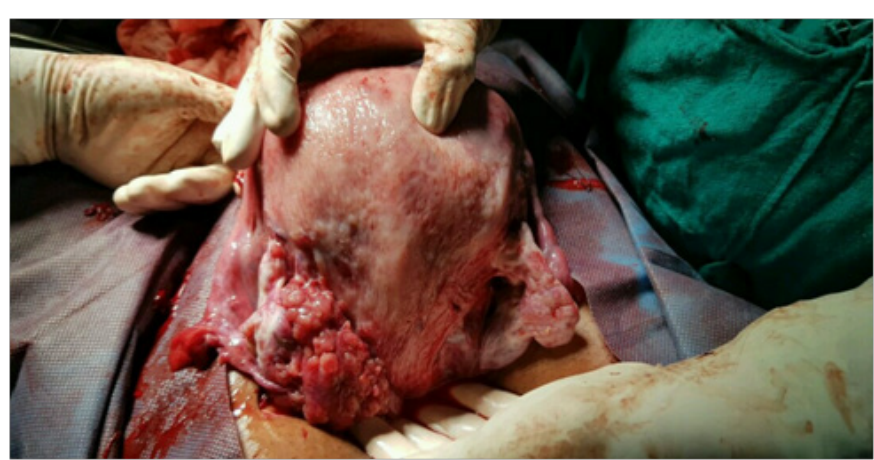

Figure I Incidental detection of left ovarian atypical endometriosis during LSCS extending over posterior uterine wall upto the pouch of Douglas

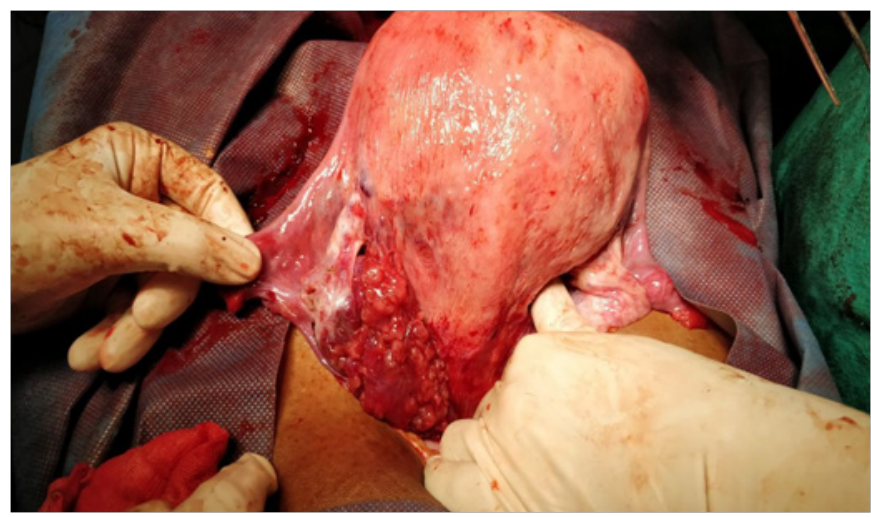

Figure 2 Left tube is free from the polypoid atypical endometriosis

\section{Discussion}

Endometriosis is a benign disease defined by the presence of endometrial glands and stroma outside the uterus and is associated with both pelvic pain and infertility. The prevalence of endometriosis 
is $6-10 \%$ in women of reproductive age group. ${ }^{4,5}$ Nearly $20-25 \%$ of patients are asymptomatic. ${ }^{1}$

Risk factors are early menarche, short menstrual cycles, ${ }^{6,7}$ nulliparity, 1st degree relative, drug exposure to DES, Dioxin and in younger age group it is usually associated with müllerian anomalies and cervical or vaginal obstruction. ${ }^{8}$ In the recent years the etiopathogenesis is also attributed to autoimmune disorder. Prolonged lactation and multiparity are protective. ${ }^{4}$ The clinical features of endometriosis are varied, and the presentation depends on the site of growth and severity of disease. Although usual presentation being six D's: dysmenorrheal (most common symptom), disorders of menstruation, dyspareunia, dyschezia, dysuria and dull aching chronic pain abdomen. Three types of endometriosis have been described: peritoneal superficial endometriosis, ovarian endometriomas, and deep infiltrating endometriosis (DIE). DIE usually involves the uterosacral ligaments, the rectovaginal space, and the upper third of the posterior vaginal wall, the bowel, and the urinary tract. ${ }^{6}$ Endometriosis is primarily found in the pelvis: on the ovaries most commonly, uterus, fallopian tubes, uterosacral ligaments, broad ligaments, round ligaments, cul-de-sac or ovarian fossa, as well as on the appendix, large bowel, ureters, bladder, or rectovaginal septum. Extra-pelvic locations of endometriosis are rare, but can include the upper abdomen, diaphragm, abdominal wall or abdominal scar tissue. Peritoneal implants of endometriosis and the presence of endometriomas are more common on the left side of the pelvis than the right. The position of the sigmoid colon creates a sequestered microenvironment around the left adnexa, which facilitates implantation of endometrial cells regurgitated through the left tube. ${ }^{4}$

Laparoscopy with histologic examination of excised lesions is the gold standard for the diagnosis of endometriosis. The classic peritoneal implant is a blue-black "powder burn" lesion with varying amounts of surrounding fibrosis, typically observed on the ovaries and on peritoneal surfaces in the cul-de-sac, uterosacral ligaments, and ovarian fossa. ${ }^{11}$ Less commonly, disease may be found in ovarian adhesions, yellow- brown patches, in peritoneal defects, or involving the appendix. ${ }^{11}$ Red lesions are highly vascular, proliferative, and represent an early stage of disease. Pigmented lesions represent more established or advanced disease.

Endometriosis is biologically the same as basal endometrial tissue Microscopically foci of endometriosis consist of glands, stroma cells, and smooth muscle; they are supplied by nerves, lymphatic vessels, and blood vessels. ${ }^{12,13}$ Endometriosis cells express estrogen receptors $(\mathrm{ER} \alpha / \beta)$ and progesterone receptors $(\mathrm{PR} \mathrm{A} / \mathrm{B})$ and therefore respond to endocrine treatment. ${ }^{14-17}$

Treatment can be medical or surgical depending on the symptoms and time of presentation. In a young woman with minimal symptoms medical line of management can be tried, similarly a patient who has presented in the perimenopausal age group, we can wait till menopause because the symptoms regress after menopause due to withdrawal of estrogen and progesterone. Surgical line of treatment will suffice for such patients who are infertile or young and symptomatic. The hormonal therapy counteracts only the stimulus of endometriotic tissue proliferation. The overall recurrence rate is about $30 \%$ for combined therapies and about $35 \%$ for the hormonal treatment alone 19.Medical treatment for pelvic pain and suspected endometriosis involve trial of NSAIDS or oral contraceptive, if failed empirical GnRH agonist therapy plus estrogen-progestin add-back therapy or danazol is used. In case of above medical management failure and associated infertility, operative laparoscopy is done for removal of endometriosis and restoration of pelvic anatomy. In our case, the patient who was neither symptomatic nor infertile, it was an accidental diagnosis.

Approximately $0.7 \%$ to $1.0 \%$ of patients with endometriosis have lesions that undergo malignant transformation. ${ }^{4}$ Atypical glandular changes have been found in $3 \%$ to $6 \%$ of cases of ovarian endometriosis. Endometroid adenocarcinomas account for $69 \%$ of reported lesions, with the ovary being the primary site in most cases. ${ }^{4}$ So the further plan of management for the patient is to follow up with serial ultrasonography scans and markers for ovarian carcinoma for early detection and management for malignant transformation of endometriosis.

\section{Conclusion}

Atypical endometriosis was incidentally found during the caesarean section in a patient with no previous clear symptoms, which adds this case to the small number of similar cases described. In our case we decided to take biopsy of the tissue as it was highly vascular and malignancy had to be ruled out.

\section{Acknowledgments}

None.

\section{Conflict of interest}

The author declares there is no conflict of interest.

\section{References}

1. Bulletti C, Elisabetta M, Battistoni CS, et al. Endometriosis and Infertility. J Assist Reprod Genet. 2010;27(8):441-447.

2. White KC. Ovarian tumors in pregnancy: a private hospital ten year survey. American Journal of Obstetrics and Gynecology. 1973;116(4):544-550.

3. Raffi F, Amer S. Endometriosis. Obstetrics, Gynaecology and Reproductive Medicine. 2011;21(4):112-117.

4. Ueda Y, Enomoto T, Miyatake T, et al. A retrospective analysis of ovarian endometriosis during pregnancy. Fertil Steril. 201094(1):78-84.

5. Cramer DW, Missmer SA. The epidemiology of endometriosis. Ann NY Acad Sci. 2002;955:34-36.

6. Missmer SA, Hankinson SE, Spiegelman D, et al. Incidence of laparoscopically confirmed endometriosis by demographic, anthropometric, and lifestyle factors. Am J Epidemiol. 2004;160(8):784 796.

7. Troncon JK, Zani AC, Vieira AD, et al. Endometriosis in a patient with mayer-rokitansky-küster-hauser syndrome. Case Rep Obstet Gynecol. $2014 ; 164: 218-219$.

8. Barrier BF. Immunology of endometriosis. Clin Obstet Gynecol. 2010;57(3):397-402

9. Stegmann BJ, Sinaii N, Liu S, et al. Using location, color, size, and depth to characterize and identify endometriosis lesions in a cohort of 133 women. Fertil Steril. 2008;89(6):1632-1636.

10. Gylfason JT, Kristjansson KA, Sverrisdottir G, et al. Pelvic endometriosis diagnosed in an entire nation over 20 years. Am J Epidemiol. 2010;172(3):237-243.

11. Meyer R, Stoeckel W. Die Pathologie der Bindegewebe. Geschwülste und der Mischgeschwülste. Handbuch der Gynäkologie, München JF, editors, Bergmann. 1930;211-853. 
12. Mechsner S, Schwarz J, Thode J, et al. Growth-associated protein 43-positive sensory nerve fibers accompanied by immature vessels are located in or near peritoneal endometriotic lesions. Fertil Steril. 2007;88(3):581-587.

13. Leyendecker G, Wildt L, Mall G. The pathophysiology of endometriosis and adenomyosis: tissue injury and repair. Arch Gynecol Obstet. 2009;280(4):529-538.

14. Roman H, Vassilieff M, Gourcerol G, et al. Surgical management of deep infiltrating endometriosis of the rectum: pleading for a symptom-guided approach. Hum Reprod. 2011;26(2):274-281.
15. Dede M, Yenen MC, Yilmaz A, et al. Treatment of incidental adnexal masses at caesarean section: a retrospective study. Int J Gynecol Cancer. 2007;17(2):339-341.

16. Ulker V, Gedikbasi A, Numanoglu $\mathrm{C}$, et al. Incidental adnexal masses at caesarean section and review of the literature. J Obstet Gynecol Research. 2010;36(3):502-505.

17. Howard W, Jones, John A Rock. Ti Linde's operative gynecology. 11th edn. Endometriosis: 402-444. 